\title{
In Memoriam Ramzi Cotran, M.D.
}

Dr. Ramzi Cotran, Chair of Pathology at Harvard's Brigham and Women's Hospital, died on October 23 of metastatic melanoma. His passing surely closes an era in contemporary pathology, one shaped by Ramzi's energetic and unfailing devotion to the advancement of pathology as a premier discipline, a unique discipline tying basic science knowledge to clinical practice. Although many have contributed to this evolution, Ramzi's influence has been pervasive. Respected and admired by clinicians and researchers alike, Ramzi has provided leadership and served as an exemplary role model for legions of trainees and colleagues. As colleagues, and on behalf of the executive editorial board of Laboratory Investigation, we bid our friend farewell. One

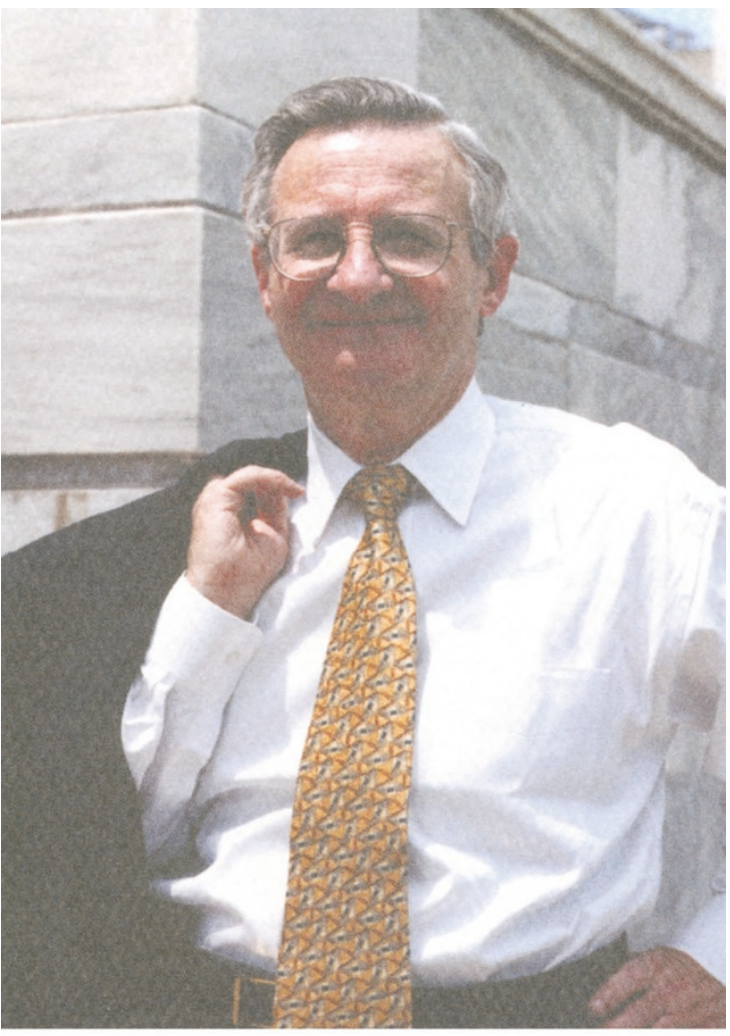

RAMZI S. COTRAN, M.D. tigative Pathology), and a member of the American Society of Nephrology and the United States and Canadian Academy of Pathology. Ramzi also served on numerous committees and editorial boards, including the editorial board of Laboratory Investigation. This list of positions and honors is markedly abbreviated and does not include his unofficial roles as moral compass, wise counselor, tireless advocate, and generous friend of pathologists (and pathology chairs) all over the world. I had the privilege of introducing Ramzi when he received the Gold Headed Cane Award for lifetime achievement from the American Society of Investigative $\mathrm{Pa}$ thology in 1998. I thought I had done a fairly good job of recounting his biography. Afterwards, Ramzi, in of our number, Dr. Jordan Pober, had the good fortune to have trained directly under Ramzi. His more personal reflections on this great man follow.

\section{For the Editorial Board, José Costa, M.D. Jon S. Morrow, M.D., Ph.D. Editors-in-Chief}

\section{Reflections}

Ramzi Cotran died of cancer on Monday, October 23. $\mathrm{He}$ is survived by his wife, four children, eleven grandchildren, and countless intellectual progeny. Ramzi was a noted investigator in renal and vascular pathology, the primary author of the medical students' bible, Pathologic Basis of Disease, Chairman of the Pathology Departments at both Brigham and Women's Hospital and Children's Hospital Medical Center, the Frank B. Mallory Professor of Pathology at Harvard Medical School, a member of the National Academy of Science's Institute of Medicine, a past president of the American Association of Pathologists (now the American Society for Inves- his inimitable style, told me that my speech was "pretty good," but that I "didn't get the facts quite right." I knew from ten years of working with him in the lab that getting the facts exactly right was very important to him. He would insist on controls that no one else could imagine. The members of the United States and Canadian Academy of Pathology no doubt heard a more accurate rendition of his accomplishments when Ramzi was honored with the society's Maude Abbot Prize in 1996. This past year, Ramzi was honored by Harvard Medical School with both the Lifetime Achievement Award in Mentoring and an award for advancing the careers of women. I saw Ramzi this past September shortly before the ceremony held at Brigham and Women's Hospital to unveil his official portrait. The ceremony included speeches by a number of Ramzi's colleagues as well as by some recent trainees. He told me that the trainees were the most important speakers because they are his proudest achievement. I think that everyone whose life has been touched by Ramzi would agree with him. He will be sorely missed.

Jordan S. Pober, M.D., Ph.D. 